\title{
The Impact of Skills Training on Responses to the Disclosure of Mistreatment
}

\author{
Melissa Ming Foynes and Jennifer J. Freyd \\ University of Oregon
}

\begin{abstract}
Objective: Although disclosure of mistreatment can be beneficial, the effects of disclosure are largely contingent on the quality of responses received. An experimental design was used to evaluate a set of skills-training materials (STMs; Foynes \& Freyd, 2010) designed to improve supportive responding to the disclosure of mistreatment experiences. Method: Dyads of university students and community members $(N=110)$ were randomly assigned to condition (experimental or control) and role (discloser or listener). After completing a series of questionnaires, the "discloser" was asked to describe an experience of mistreatment not previously disclosed to the "listener." Dyads completed postdisclosure questionnaires, reviewed a set of STMs regarding either healthy lifestyle improvements (control) or supportive listening techniques (experimental), and completed a quiz. A second experience of mistreatment was disclosed and a final set of questionnaires was completed. Results: Results indicated that listeners in the experimental condition demonstrated significantly fewer unsupportive behaviors than listeners in the control condition. Listeners who started with high levels of unsupportive behaviors benefitted the most from the STMs. Conclusions: The STMs developed for this study are relatively short in length, easy to administer, and informed by disclosers' perceptions of supportive behaviors. Thus, these materials could serve as a preliminary step toward developing more effective ways of providing lay people with education on enhancing supportive listening behaviors.
\end{abstract}

Keywords: skills training, disclosure, mistreatment, social support

In mainstream American culture, disclosure is often viewed as a healthy, adaptive, and socially accepted form of coping (Rime, 1995). In fact, within this cultural context, many benefits of both verbal and written disclosure of various types of mistreatment have been identified (e.g., Hemenover, 2003; Lepore, Ragan, \& Jones, 2000). In understanding these benefits, it is im-

\footnotetext{
Melissa Ming Foynes and Jennifer J. Freyd, Department of Psychology, University of Oregon.

Dr. Melissa Ming Foynes is currently affiliated with VA Boston Healthcare System.

We thank Sanjay Srivastava for his statistical expertise and the University of Oregon's Center on Diversity and Community and the Fund for Research on Trauma and Oppression (PI, Jennifer J. Freyd) for funding part of this research. We would also like to acknowledge those people who participated in this research and were willing to share their experiences; we are extremely grateful for their contributions.

Correspondence concerning this article should be addressed to Melissa Ming Foynes, VA Boston Healthcare System, Psychology Service (116B), 150 South Huntington Avenue, Boston, MA 02130. E-mail: melissa.foynes2@ va.gov
}

portant to note that there is also empirical support for the notion that the effects of disclosure are largely contingent on social context and the quality of responses received following disclosure (e.g., Ahrens, Campbell, Ternier-Thames, Wasco, \& Sefl, 2007; Ullman, 2007). That is, disclosing and receiving a negative reaction predict worse psychological outcomes than both nondisclosure (Major, Cozzarelli, Sciacchitano, Cooper, \& Testa, 1990) and disclosures met with supportive responses (e.g., Figueiredo, Fries, \& Ingram, 2004; Ullman, 2007). This suggests that disclosure in and of itself is not sufficient for benefit (Coker et al., 2002). Despite the importance of supportive responses, only a few studies have examined the effectiveness of skills-training interventions aimed at enhancing supportive responses (Ancel, 2006; Hatcher et al., 1994; Pollak et al., 2007; Taylor, Cook, Green, \& Rogers, 2001). Even fewer have conducted empirical evaluations of such interventions (Cordova, Ruzek, Benoit, \& Brunet, 2003; Hansen, Resnick, \& Galea, 2002; Resnick, 1998). Given the limitations of prior 
research in this area, we used an experimental design to assess whether empathic listening skills and supportive responses to disclosures of mistreatment could be enhanced via a brief set of skills-training materials (STMs) developed specifically for this study.

In the current study, we attempted to improve on existing research in several domains. As mentioned previously, although there is limited empirical research regarding listening skills training, the importance of empathic responding and listening has been implicated in many areas of research (e.g., Bylund \& Makoul, 2002; Forrester, Kershaw, Moss, \& Hughes, 2008; Janusik, 2008; Pollak et al., 2007; Taylor et al., 2001). However, in the majority of this research, the effectiveness of such training is not determined by the person disclosing. The possibility for support attempts to be well intentioned but to be experienced as negative or harmful, nonetheless (e.g., Ahrens et al., 2007), underscores the importance of gaining insight into the discloser's perspective, rather than assuming that certain responses are helpful (Ahrens et al., 2007). To emphasize the importance of disclosers' perceptions in defining what is considered "supportive," we used disclosers' assessment of listeners' behaviors as the unit of analysis. Second, we increased ecological validity by studying disclosures related to personal experience within the context of natural relationships. More specifically, we examined the effects of skills training on responses to disclosure of a wide range of types of mistreatment that are not only common in the general population (see Lantz, House, Mero, \& Williams, 2005) but also are often distressing (e.g., bereavement, betrayal of trust, bullying, feelings of abandonment, loss of an important relationship). Lastly, we implemented an experimental design to reduce retrospective report bias and control for confounding variables.

\section{Rationale for the Current Study}

An abundance of prior research has documented the importance of social support, but the effectiveness of various social support interventions is less clear because of variations in the types of interventions and populations studied. Common methodological limitations in this area of research include lack of comprehensive measures of social support, small sample sizes, inattention to random assignment, inclusion of descriptive rather than inferential statistics, and overreliance on self-report data (Hogan, Linden, \& Najarian, 2002). Recommendations that interventions focus on improvement of social support within the natural support network via skills training rather than provision of direct support have arisen from this research. According to this logic, lack of support is often related to the failure of the support network to be supportive rather than an individual's inability to foster supportive relationships or articulate needs (Hogan et al., 2002). Relatedly, research suggests that recipients of disclosure of various mistreatment experiences are less likely to be mental health or social service professionals and more likely to be friends and family members (e.g., Coker et al., 2002; Fisher, Daigle, Cullen, \& Turner, 2003; Ullman \& Filipas, 2001). Taken together, this research further emphasizes the importance of teaching family members and friends, the most common recipients of disclosure, how to be more supportive when experiences of mistreatment are disclosed.

The body of research regarding responses to the disclosure of mistreatment has generated important findings, but the majority has been in the form of retrospective, self-report methodologies. Fewer studies have implemented designs in which disclosure is elicited, and observed, in the research context (e.g., Fritz, Nagurney, \& Helgeson, 2003; Lepore, Fernandez-Berrocal, Ragan, \& Ramos, 2004; Lepore et al., 2000; Pistrang, Barker, \& Rutter, 1997). Some of these studies have examined important aspects of self-disclosure (e.g., individual differences, reciprocity, gender, depth of relationship; e.g., Dindia, Fitzpatrick, \& Kenny, 1997); however, only two of these studies examined the impact of negative responses to disclosure in a laboratory setting in which there was actual human interaction, instead of relying solely on retrospective accounts of disclosure (e.g., Lepore et al., 2000, 2004). In addition, the findings have been mixed.

In the first of these two studies, participants assigned to "talk alone" and speak with a "validating confederate" following a stressful video clip reported significantly lower levels of perceived stress and intrusive thoughts than participants assigned to a "no talk" control condition. It is interesting that participants in the "invalidating confederate" condition fared neither bet- 
ter nor worse than participants in the three other conditions (Lepore et al., 2000). In a similar study, participants who disclosed to a "challenging" confederate demonstrated the largest decreases in distress (Lepore et al., 2004). Although one strength of these studies is their experimental design, their ecological validity may be limited in terms of the nature of the stimuli meant to induce distress (e.g., timelimited exposure, content likely low in personal significance and level of direct threat to participants) and the disclosure interaction itself (e.g., brief, scripted response between two strangers without a real relationship). Thus, it is difficult to know whether these results generalize to more personal disclosures about events that have been directly experienced and are being shared in the context of intimate or important social relationships.

In the present study, we examined two hypotheses:

Hypothesis 1: Listeners in the experimental condition will respond more supportively (e.g., lower scores on the Unsupportive Social Interactions Inventory [USII; Ingram, Betz, Mindes, Schmitt, \& Smith, 2001] as rated by disclosers) to the second disclosure than listeners in the control condition, taking into account their initial USII scores.

Hypothesis 2: Disclosers in the intervention condition will experience more positive benefits (e.g., increased positive emotion, decreased negative emotion, decreased stress and arousal) than disclosers in the control condition, taking into account predisclosure levels.

\section{Method}

\section{Participant Recruitment}

The sample comprised 110 dyads of university students and friends or family of these students who could have been university students but were not required to be. This generated a total sample of 220 participants, most of whom were young adults ranging in age from 18 to years $25(96.4 \%)$. Recruitment began with the Department of Psychology's Human Subjects Pool at the University of Oregon. These participants were given academic credit for their participation. Prior to running the study, approval was granted by the University of Oregon's Institutional Review Board.

On logging into the electronic system, participants viewed a list of available studies designated with names of trees. Participants could click on any of these studies to view a list of available timeslots and access eligibility requirements (e.g., 18 years of age or older, fluent in spoken English, ability to find a friend of at least 3 months [either within or outside of the university] who would also be willing to participate during the same time). Data were not collected regarding the number of eligible participants who ultimately did not participate because of difficulty finding a friend. Although over two thirds of our sample did report a history of trauma, this was not a requirement for participation.

For the majority of the study, the second individual in each dyad was given \$12 as compensation if he or she was not eligible for credit. After the grant funding ended, the second individual could choose to participate as a volunteer if he or she was not eligible to participate for credit. Approximately 55 pairs of people participated in the study after this change was implemented. There were approximately 11 pairs in which one person participated as a volunteer; in the remainder, both participated for credit.

\section{Participant Characteristics}

The majority of the participants were women $(61 \%)$, ranged in age from 18 to 43 years $(M=19.59, S D=3.26)$, and identified as European American only (75\%). Approximately $92 \%$ were born in the United States, and approximately $89 \%$ reported that both of their parents were born in the United States. Those who participated before and after the change in compensation were similar on all demographic variables; that is, the majority of both samples were $18-25$ years old (95\% and $100 \%)$, female $(65 \%)$, Caucasian $(78 \%$ and $81 \%)$, and U.S.born (99 and 97\%), with U.S.-born parents (96\% and 93\%). Given these similarities, participants were treated as one group in the remainder of analyses. Approximately $70 \%$ of the sample indicated that they experienced at least one type of traumatic event on the Betrayal Trauma Inventory (BTI), with $42.3 \%$ of the sample indicating that they had experienced at 
least one form of emotional, physical, or sexual abuse.

In approximately $50 \%$ of the pairs, both participants were women. In approximately $27 \%$ of the pairs, one participant was a man and one was a woman, and in approximately $23 \%$ of the pairs, both participants were men. Because of random assignment to condition, the gender composition of the dyads was not evenly distributed across conditions. The percentages of dyads in the control group were as follows: $41.8 \%$ of female-female dyads, $60 \%$ of femalemale dyads, and $64 \%$ of male-male dyads.

\section{Procedure}

The study lasted approximately $90 \mathrm{~min}$. The 110 pairs of participants were randomly assigned in advance to an experimental or control condition by the principal investigator such that 53 pairs were in the experimental condition and 56 pairs were in the control condition (given missing data on the USII, only 109 dyads were included in that particular analysis). Research assistants were blind to condition; the research assistant was made aware of condition because of participant questions in only two pairs.

Participants completed a series of initial questionnaires after giving informed consent. During this time, participants were asked to write on index cards two experiences in which they felt mistreated by someone close to them (e.g., who they trusted, cared for, or depended on). Participants completed all questionnaires in separate rooms and were in the same room only for the disclosure portions of the study.

On reuniting the pair, the research assistant flipped a coin to determine who would be assigned which role (e.g., discloser or listener) and then shuffled the discloser's two cards to select the first disclosure topic; thus, the order in which the two events were disclosed was presumably random. The discloser (Participant A) was then given the following instructions: "Please talk about the experience on this card. Remember, if you have told your partner about the events in a general way, please tell him/her the important details or aspects of the event you have not previously discussed." To Participant B (the listener), the researcher said, "Your job is to listen to your friend." Research assistants were given an experimenter script as well as a list of scripted responses to possible questions to maintain consistency in interacting with the participants.

The disclosure interaction was videotaped for $8 \mathrm{~min}$ for later coding and future analyses (not included in the present study); both participants then completed a series of postdisclosure questionnaires. Participants were then given sealed envelopes containing written STMs regarding either healthy lifestyle improvements (control condition) or supportive listening techniques (experimental condition). Both participants in each pair received the same materials. Participants were given 10 min to study this material and 5 min to take a short quiz on this material. While studying, participants were given an index card on which they could take notes and to which they could refer during the quiz. After completing the quiz, there was a second 8-min disclosure in which the discloser was asked to discuss the experience written on the second index card. This was followed by completion of a second set of postdisclosure questionnaires and a debriefing period.

\section{Materials}

\section{Initial self-report measures.}

BTI. A shortened version of the BTI (Freyd, DePrince, \& Zurbriggen, 2001) was used to assess prior history of trauma. The BTI has been used in several studies (e.g., Freyd et al., 2001; Freyd, Klest, \& Allard, 2005) and adheres to previous recommendations of screening for multiple types of trauma and multiple events within those types (DePrince, 2001; Green et al., 2000). Further support for the use of the BTI comes from prior research indicating a high level of agreement $(62-77 \%)$ between the BTI and another trauma inventory, the Brief Betrayal Trauma Survey (Goldberg \& Freyd, 2006), despite wording differences across the measures (DePrince, 2001). It has also been suggested that the BTI assesses key features of childhood trauma in ways that individuals are able to make sense of, facilitating consistency in responding (DePrince, 2001).

Experiences of mistreatment. Participants were asked to think of at least two experiences in which they were mistreated or let down by someone they trusted, cared for, or depended on that they had not told their partner about before. They were then given examples of experiences 
and asked to choose two that they would be willing to talk to their partner about.

STMs (Foynes \& Freyd, 2010). These written materials included separate informational handouts and quizzes for experimental and control participants. (Materials can be found at http://dynamic.uoregon.edu/ jjf/ disclosure/ and may be copied, distributed, or otherwise reused or modified by first contacting the author listed on the website for reprint permission.) The handouts and quizzes were matched on length, word count, level of vocabulary, and structure. Several people other than the principal investigators reviewed various drafts of these documents to help improve clarity and make the documents as similar as possible across conditions.

The experimental handout focused on describing nonverbal and verbal ways of supportively responding to disclosure. Material for this handout was derived from findings from prior research (e.g., Coulehan et al., 2001; Foynes \& Freyd, 2008; Frankel \& Stein, 1999; Pollak et al., 2007; Robertson, 2005; Smith \& Hoppe, 1991). First, suggestions were given regarding attentive body language (e.g., facial expressions, posture, eye contact). Second, verbal skills meant to encourage the speaker to continue were also emphasized, such as refraining from changing the topic, reflecting back the emotion being described, allowing for silence, using brief encouraging statements to demonstrate active listening, and asking open-ended questions. Finally, participants were encouraged to use words that conveyed support by refraining from providing reassurance in a way that could be perceived as minimizing, striving to be nonjudgmental, validating emotions in a genuine tone, pointing out the person's strengths, abstaining from offering unsolicited advice, and focusing on the discloser's experience rather than the listener's. For each suggestion, examples of statements or behaviors were given in parentheses to guide participants.

Material for the control handout was derived mainly from prior research and educational materials focusing on three main aspects of living a healthy lifestyle: nutrition (U.S. Department of Health and Human Services \& U.S. Department of Agriculture, 2005), exercise (U.S. Department of Health and Human Services, 1996), and sleep hygiene (Taheri, 2006; Yager \& Thorpy, 2001).

\section{Postdisclosure questionnaires.}

USII (Ingram et al., 2001). The USII is a 24-item measure used to assess unsupportive or upsetting responses given by others regarding a stressful life experience (e.g., "Changed the subject before I wanted to"; "Did not seem to know what to say, or seemed afraid of saying or doing the 'wrong' thing"; "Told me to be strong, to keep my chin up, or that I should not let it bother me"; "Seemed disappointed in me"). The USII was completed by the discloser and listener (i.e., the discloser rated the listener's level of unsupportive behaviors and the listener rated his or her own unsupportive behaviors). Exploratory and confirmatory factor analyses have demonstrated adequate internal consistency and reliability for the total score on this scale $(\alpha=.90$; Ingram et al., 2001). Strong construct (Ingram et al., 2001) and predictive validity (e.g., Figueiredo et al., 2004; Mindes, Ingram, Kliewer, \& James, 2003) have also been demonstrated. In the present study, the disclosers' ratings of the listeners' behaviors demonstrated adequate reliability both pre$(\alpha=.74)$ and postdisclosure $(\alpha=.82)$.

Positive and Negative Affect ScaleExpanded Version (PANAS-X; Watson \& Clark, 1994). The PANAS-X is a 60-item adjective checklist, including "negative affect" adjectives (e.g., irritable, upset) and "positive affect" adjectives (e.g., interested, strong) that respondents rate on a scale from 1 (very slightly/ not at all) to 5 (extremely), generating two higher order subscales (Positive and Negative Affect). Seven lower order scales regarding more specific affect states have also been constructed (e.g., fear, sadness, guilt, hostility, shyness, fatigue, and surprise). Prior research on university, community, and clinical samples demonstrates high internal consistency and divergent validity for the Positive and Negative Affect subscales. Strong convergent validity has been demonstrated between self- and peer ratings and between scores on the PANAS-X and other measures that assess multiple levels of affect (e.g., Profile of Mood States; Watson \& Clark, 1994). Research supports the use of the PANAS-X as a measure of short-term affect (Watson \& Clark, 1994) and its sensitivity to fluctuations in external and internal circumstances (Watson \& Clark, 1994). The PANAS-X has been used on adolescent and young adult populations (e.g., Heaven \& 
Ciarrochi, 2007; Hussong \& Hicks, 2003). In this study, the higher order Positive and Negative Affect subscales were used to assess the affective state for both discloser and listeners before and after the second disclosure. Adequate internal consistency was demonstrated for both participants pre- and postdisclosure for both subscales (ranging from $\alpha=.73$ to $\alpha=$ $.90)$.

Stress Arousal Checklist (SACL; Mackay, Cox, Burrows, \& Lazzerini, 1978). The SACL is a 30-item measure used to assess stress and arousal levels using adjectives often associated with descriptions of stressful experiences (e.g., tense, peaceful, energetic, sluggish). For each adjective listed, participants are asked to rate the extent to which they feel each adjective describes their current feelings. Prior factor analyses have been conducted and have identified a two-factor structure: Stress $(\alpha=.86)$ and Arousal $(\alpha=.74$; Fischer \& Donatelli, 1987; Mackay et al., 1978). SACL scores have been shown to increase in response to stressors (e.g., Burrows, Cox, \& Simpson, 1977; King, Burrows, \& Stanley, 1983) and significantly correlate with other physiological measures of stress (Burrows et al., 1977; Mackay et al., 1978). Adequate internal consistency was demonstrated for both participants pre- and postdisclosure for the Stress and Arousal subscales (ranging from $\alpha=.72$ to $\alpha=.89$ ).

\section{Results}

\section{Descriptive Analyses}

\section{Disclosure topics-Experiences of mis-} treatment. Eighteen categories describing the experiences of mistreatment that participants chose to disclose were created; a 19th category was used for topics deemed as miscellaneous either because they fit into multiple categories, none of which could be deemed as primary or central, or because their uniqueness/ specificity would have otherwise necessitated the creation of an additional category to describe that singular topic. Both the disclosers' first $(n=110)$ and second $(n=110)$ topics were categorized as follows: verbal abuse $(n=27,12.3 \%)$; physical abuse or violence $(n=24,10.9 \%)$; relationship distress (e.g., breakups, divorce, cheating; $n=21,9.5 \%$ ); abandonment (e.g., not being supported when expected, getting "ditched"; $n=20,9.1 \%$ ); betrayal of trust (e.g., being lied to or deceived; $n=16,7.3 \%$ ); feeling let down ( $n=14,6.4 \%)$; blamed/felt guilty or unworthy ( $n=12,5.5 \%)$; drug use/ abuse $(n=11,5 \%)$; sexual abuse $(n=11,5 \%)$; being taken advantage of (financially, physically/sexually, or in another way; $n=10,4.5 \%$ ); physical abandonment or neglect $(n=9,4.1 \%)$; death (either murder or death unrelated to suicide/illness; $n=8,3.6 \%$ ); broken promises $(n=7,3.2 \%)$; suicide attempts/ideation, actual suicide, self-harm ( $n=6,2.7 \%)$; teasing/ bullying/relational aggression $(n=6,2.7 \%)$; trusted person shared a secret or spread a rumor $(n=6,2.7 \%)$; illness/injury $(n=5,2.3 \%)$; miscellaneous ( $n=4,1.8 \%)$; and distressing memory of being left alone/lost $(n=3,1.4 \%)$.

\section{Tests of Hypotheses}

Given issues of dependency in analyzing dyadic data, the dyad, rather than each individual person, was treated as the unit of analysis (110 total dyads). In following the recommendations put forth by Kenny, Kashy, \& Cook (2006) for dyadic data, we used the standard dyadic design and data structure. Thus, this approach allowed us to account for within-dyad bidirectional effects of partners' behaviors and mood states on one another. If any participant had missing data on the dependent variable being analyzed, the entire pair was excluded from that particular analysis, resulting in sample sizes lower than those reported above for some analyses.

To examine the effect of the gender composition of the dyad on each dependent variable (USII, PANAS-Positive Affect subscale [PA], PANAS-Negative Affect subscale [NA], SACL-Stress subscale [SACL-S], and SACL-Arousal subscale [SACL-A]), we conducted five $3 \times 2$ univariate analyses of variance. In each analysis, the between-subjects factors were gender composition of the dyad (female-female, male-female, and male-male) and condition (experimental and control). Predisclosure scores were entered as covariates. There were no significant effects of gender and no significant interactions between gender and condition $(p s>.05)$. Because there were no significant gender effects, all dyads were used in each analysis, and no further examinations of gender were conducted. 
Hypothesis 1. A regression analysis was conducted using disclosers' ratings of listeners' behaviors as the dependent variable (e.g., listeners' postdisclosure USII score as rated by disclosers). In Step 1, predictors were group (experimental or control) and listeners' centered predisclosure USII scores (as rated by disclosers). Step 2 tested for the additional variance in postdisclosure USII scores accounted for by the interaction between group and predisclosure scores; overall, the second model accounted for approximately $56 \%$ of the variance in postdisclosure USII scores (adjusted $R^{2}=.562$ ). The inclusion of the interaction term in the second model resulted in an additional explanation of $6.8 \%$ of the variance, $R^{2}$ change $=.068 ; F(1$, $105)=16.84, p<.01$ (see Table 1 ). In this model, condition, predisclosure USII scores, and the interaction between condition and predisclosure USII scores were all significant predictors $(p s<.05)$.

To clarify the nature of the interaction, we created graphs using estimated values according to the recommendations of Judd, McClelland, and Ryan (2009; see Figure 1). For listeners with high predisclosure scores (i.e., those people who started off with a high level of unsupportive behaviors), being in the experimental condition was on average associated with lower postdisclosure USII scores compared with being in the control condition. For listeners with low predisclosure scores, the STMs were less effective.

Table 1

Summary of Hierarchical Regression Analysis for Variables Predicting Listeners' Postdisclosure Unsupportive Social Interactions Inventory (USII) Scores $(n=109)$

\begin{tabular}{|c|c|c|c|}
\hline Variable & $B$ & $S E B$ & $b$ \\
\hline \multicolumn{4}{|l|}{ Step 1} \\
\hline Condition ${ }^{\mathrm{a}}$ & -.067 & .032 & $-.144^{*}$ \\
\hline Predisclosure USII ${ }^{\mathrm{b}}$ & .729 & .074 & $.677^{* * *}$ \\
\hline \multicolumn{4}{|l|}{ Step 2} \\
\hline Condition & -.076 & .030 & $-.165^{*}$ \\
\hline Predisclosure USII & .900 & .081 & $.836^{* *}$ \\
\hline Interaction $^{c}$ & -.642 & .156 & $-.308^{*}$ \\
\hline \multicolumn{4}{|c|}{$\begin{array}{l}\text { Note. } R^{2}=.506 \text { for Step } 1 ; \Delta R^{2}=.068 \text { for Step } 2(p \mathrm{~s}< \\
.01) . \\
{ }^{\mathrm{a}} \text { Condition }=\text { experimental or control. }{ }^{\mathrm{b}} \text { Covariate }=\text { lis- } \\
\text { teners' predisclosure score on USII centered around the } \\
\text { mean. }{ }^{\mathrm{c}} \text { Interaction between condition and covariate. } \\
{ }^{*} p<.05 .{ }^{* * *} p<.01 .\end{array}$} \\
\hline
\end{tabular}

Hypothesis 2. To examine the effect of condition on changes in disclosers' affect, we conducted two regression analyses separately for positive (PA) and negative affect (NA). For both analyses, postdisclosure affect score was the dependent variable; predictors included group (experimental or control) and disclosers' centered predisclosure affect scores. For PA, this model was significant, $F(2,97)=69.05$, $p<.01$, with predisclosure PA score as the only significant predictor. For NA, this model was significant, $F(2,97)=49.47, p<.01$, with predisclosure NA score the only significant predictor. Higher predisclosure levels of PA and NA were associated with significantly higher levels of postdisclosure levels of PA and NA.

In the second set of regression analyses, we conducted two separate analyses to examine disclosers' level of stress (SACL-S) and arousal (SACL-A). For both analyses, the disclosers' postdisclosure score was the dependent variable; group (experimental or control) and disclosers' centered predisclosure score were predictors. For SACL-S, this model was significant, $F(2,100)=48.71, p<.01$, with predisclosure SACL-S score as the only significant predictor. For SACL-A, this model was significant, $F(2,101)=49.98, p<.01$, with only predisclosure SACL-A as a significant predictor. Disclosers who had higher levels of stress and arousal prior to the disclosure had significantly higher levels of stress and arousal following the disclosure.

\section{Discussion}

In this study, we examined the effectiveness of a brief set of STMs in enhancing supportive responses to disclosure. We studied disclosures in the context of real relationships, in real time, to increase ecological validity and reduce retrospective report bias. An additional advantage to the implementation of this experimental design was the ability to control for changes that might occur naturally over time (e.g., from the first to second disclosure) because of factors such as learning or increased level of comfort. Furthermore, this approach allowed us to control for general effects attributable to the receipt of a set of STMs.

Results indicated that people in the experimental condition, compared with those in the control condition, demonstrated a significantly 


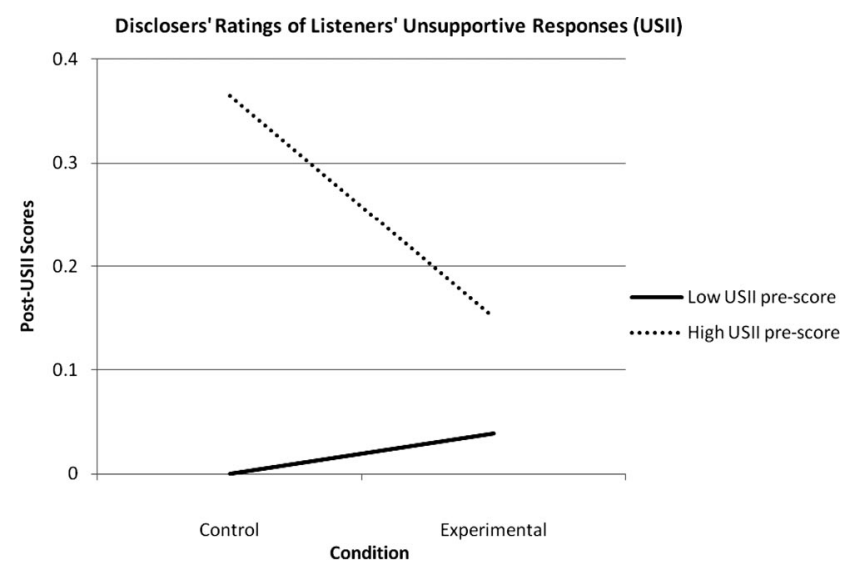

Figure 1. Listeners' postdisclosure Unsupportive Social Interactions Inventory (USII) scores accounting for predisclosure scores for both experimental $(n=53)$ and control $(n=56)$ conditions.

greater decrease in unsupportive behaviors (according to the perspective of the discloser) following receipt of the STMs, taking predisclosure levels of unsupportive behaviors into account. Given the research mentioned previously regarding the importance of accessing disclosers' perspectives, the fact that the disclosers observed and reported significant improvements in the support the listeners provided makes these findings particularly interesting.

In addition, we found that the STMs were most effective in decreasing unsupportive behaviors in the group of listeners with high predisclosure levels of unsupportive behaviors. Because the STMs were designed as an introduction to techniques that could increase supportive behaviors, this finding makes sense. That is, people who do not start off responding supportively to disclosure may have more to learn or change about their behaviors and, therefore, may find these materials more useful; on the other hand, people who initially responded more supportively, either naturally or because of training or experience, may not have benefitted as much from a basic introduction. Instead, individuals with more advanced skills may demonstrate greater improvements following more in-depth skills training. For instance, there may be a floor effect in which people who demonstrated low scores on this measure of unsupportive behaviors do not have much room for improvement (e.g., they cannot score less than a zero on this measure) and may need more advanced STMs to refine their skills. As such, these individuals may also need to be assessed with a more nuanced measure of unsupportive behaviors to evaluate their progress.

An unexpected finding was the lack of a statistically significant impact of listeners' levels of unsupportive behaviors on disclosers' mood or stress level. Although the few studies that have previously examined the impact of unsupportive behaviors on disclosure have generated mixed findings, it is also important to note that some of the measures used in prior research to assess mood (e.g., Fogarty, Curbow, Wingard, McDonnell, \& Somerfield, 1999; Lepore, Fernandez-Berrocal, Ragan, \& Ramos, 2004), physiological response (e.g., Lepore, Ragan, \& Jones, 2000, Lepore et al., 2004), and distress (e.g., Lepore et al., 2004) have varied. Thus, it is possible that changes in the present study may have occurred in a more nuanced or subtle way than these measures were sensitive enough to detect. Furthermore, it is possible that disclosers experienced benefits that were not related to mood or stress or sufficiently captured by these constructs. For example, in the current study, we did not assess changes in intrusive thoughts that could result from disclosure, which has been a focus of prior research (e.g., Lepore et al., 2000, 2004). Another possibility is that following disclosure, disclosers might feel more understood, more able to make sense of their experiences, or feel closer or more connected to the listeners; such changes were 
not assessed here. On the other hand, it is also possible that disclosure of mistreatment may exacerbate distress if such disclosures elicit negative responses in listeners. To clarify these possibilities, future research should include a broader range of outcome measures.

\section{Limitations}

This study may provide a foundation for future research, but several limitations related to the sample and design are of note. First, certain demographic characteristics of the sample may limit generalizability to other groups, underscoring the importance of interpreting the present findings within context. That is, the disclosure processes and supportive behaviors we observed may be strongly associated with the demographics of our sample; thus, not all of the findings may remain if a sample with different demographics is examined.

For instance, this sample comprised mostly pairs of female college students who were friends, around the age of 20, making it difficult to examine the ways in which disclosure processes and responses to disclosure may vary as a function of gender, age, socioeconomic status, and relationship types. In fact, the associations among and interactions between disclosure and various demographic variables (e.g., gender, socioeconomic status, ethnicity) have been shown to be quite complex (Consedine, Sabag-Cohen, \& Krivoshekova, 2007). Gender, for instance, may interact with relationship type such that women may self-disclose to a greater extent in the context of more intimate relationships, whereas men may self-disclose to a greater extent in the context of less intimate relationships (Consedine et al., 2007). It is also possible that these dynamics may change as a function of the type of experience that is being disclosed (Consedine et al., 2007). Although we did examine the impact of gender composition of the dyad on each dependent variable and found neither significant effects of gender nor any significant interactions between gender and condition, the sample sizes for each type of dyad were quite different such that most dyads were female-female. Thus, the lack of gender differences may be attributable to a lack of power. Gender composition of the dyad may also be confounded with relationship type such that same-gender dyads were more likely to be friendships, whereas different-gender dyads were more likely to be romantic relationships. It is important that these comparisons and distinctions be made in future research.

The majority of the participants in our sample identified as European Americans born in the United States who had U.S.-born parents. With such an ethnically and culturally homogeneous sample, it is difficult to gain understanding of the ways in which such factors influence the conceptualization of disclosure, the perceived utility of disclosure, barriers and facilitators to disclosure, and responses to disclosure. Thus, it is possible that the findings in the current study represent what young European Americans who were born in the United States view as supportive and do not define responses to disclosure that would be considered effective across various cultural and ethnic groups.

In terms of the study design, one limitation of this study involved the lack of examination of certain factors on disclosure (e.g., characteristics of partner relationship, number or type of previous traumatic events experienced). Second, the study did not include long-term followup. Although the findings are promising, it is unknown whether these changes are sustainable over time, may affect the relationship between participants, and generalize to future interactions and other relationships. Inclusion of longterm follow-up would also allow examination of changes in participants' expectations of responses to disclosure and how such expectations affect perceptions of listeners' behaviors. In addition, it is unclear whether the skills training component influenced specific listening behaviors or acted as a means of raising general awareness of the importance of listening and being supportive. Additional research deconstructing the STMs to clarify which elements are the most useful in enhancing supportive responses will be important. Such findings will guide future revisions of the STMs and facilitate identification of areas for further elaboration and emphasis in the STMs.

\section{Implications}

Although other STMs like this may exist in the community (e.g., New Jersey Self-Help Group Clearinghouse, n.d.), those developed for the purposes of the current study have several advantages. First, these materials have been in- 
formed by disclosers' perceptions about what constitutes a supportive response and integrate findings from prior research. Second, these materials have garnered preliminary empirical support regarding their effectiveness. Third, they are relatively short in length and can be flexibly administered in a brief format in a variety of situations. Fourth, because they are written, they do not require professional expertise for administration and are cost efficient. The wider distribution of these materials may help address assumptions about what is helpful and provide guidance that makes the task of supportive listening seem more attainable. This may have the impact of increasing listeners' sense of selfefficacy in responding to others when experiences of mistreatment are disclosed and in turn may facilitate the creation of a more supportive environment in which to disclose.

\section{Conclusions}

While prior research indicates that experiences of mistreatment are common and that adjustment to such experiences often involves disclosure, the impact of negative responses to disclosure can be more harmful than the effects of nondisclosure. Friends and family are often the first to hear about experiences of mistreatment, yet many people have not received education or training in responding supportively to such disclosures, and are not naturally able to provide support in a way that is perceived as helpful. To date, research regarding constituents of supportive responses and ways of educating the general public to be supportive following disclosure has been limited. Thus, the findings reported here may serve as beginning steps for future research focused on enhancing supportive responses to the disclosure of mistreatment.

\section{References}

Ahrens, C. E., Campbell, R., Ternier-Thames, N. K., Wasco, S. M., \& Sefl, T. (2007). Deciding whom to tell: Expectations and outcomes of rape survivors' first disclosures. Psychology of Women Quarterly, 32, 38-49.

Ancel, G. (2006). Developing empathy in nurses: An inservice training program. Archives of Psychiatric Nursing, 20, 249-257.

Burrows, G. C., Cox, T., \& Simpson, G. C. (1977). The measurement of stress in a sales training sit- uation. Journal of Occupational Psychology, 50, 45-51.

Bylund, C. L., \& Makoul, G. (2002). Empathic communication and gender in the physician-patient encounter. Patient Education and Counseling, 48, 207-216.

Coker, A. L., Smith, P. H., Thompson, M. P., McKeown, R. E., Bethea, L., \& Davis, K. E. (2002). Social support protects against the negative effects of partner violence on mental health. Journal of Women's Health \& Gender-Based Medicine, 11, 465-476.

Consedine, N. S., Sabag-Cohen, S., \& Krivoshekova, Y. S. (2007). Ethnic, gender, and socioeconomic differences in young adults' self-disclosure: Who discloses what and to whom? Cultural Diversity \& Ethnic Minority Psychology, 13, 254-263.

Cordova, M. J., Ruzek, J. I., Benoit, M., \& Brunet, A. (2003). Promotion of emotional disclosure following illness and injury: A brief intervention for medical patients and their families. Cognitive and Behavioral Practice, 10, 358-371.

Coulehan, J. L., Platt, F. W., Egener, B., Frankel, R., Lin, C., Lown, B., \& Salazar, W. H. (2001). Let me see if I have this right: Words that help build empathy. Annals of Internal Medicine, 135, 221227.

DePrince, A. P. (2001). Trauma and posttraumatic responses: An examination of fear and betrayal. Dissertation Abstracts International: Section B. Sciences and Engineering, 62(6), 2953.

Dindia, K., Fitzpatrick, M., \& Kenny, D. A. (1997). Self-disclosure in spouse and stranger interaction: A social relations analysis. Human Communication Research, 23, 388-412.

Figueiredo, M. I., Fries, E., \& Ingram, K. M. (2004). The role of disclosure patterns and unsupportive social interactions in the well-being of breast cancer patients. Psycho-Oncology, 13, 96-105.

Fischer, D. G., \& Donatelli, M. J. (1987). A measure of stress and arousal: Factor structure of the Stress Adjective Checklist. Educational and Psychological Measurement, 47, 425-435.

Fisher, B., Daigle, L., Cullen, F., \& Turner, M. (2003). Reporting sexual victimization to the police and others: Results from a national-level study of college women. Criminal Justice and Behavior, 30, 6-38.

Fogarty, L. A., Curbow, B. A., Wingard, J. R., McDonnell, K., \& Somerfield, M. R. (1999). Can 40 seconds of compassion reduce patient anxiety? Journal of Clinical Oncology, 17, 371379.

Forrester, D., Kershaw, S., Moss, H., \& Hughes, L. (2008). Communication skills in child protection: How do social workers talk to parents? Child \& Family Social Work, 13, 41-51. 
Foynes, M. M., \& Freyd, J. J. (2008). Disclosure-inAction: The Responses of Close Others to First Disclosures. Poster presented at the 116th Annual Convention of the American Psychological Association, Boston, Massachusetts, August 14-17, 2008.

Frankel, R. M., \& Stein, T. (1999). Getting the most out of the client encounter: The Four Habits model. Journal of Medical Practice Management, 16, 184-191.

Freyd, J. J., DePrince, A. P., \& Zurbriggen, E. L. (2001). Self-reported memory for abuse depends upon victim-perpetrator relationship. Journal of Trauma \& Dissociation, 2(3), 5-16.

Freyd, J. J., Klest, B., \& Allard, C. B. (2005). Betrayal trauma: Relationship to physical health, psychological distress, and a written disclosure intervention. Journal of Trauma \& Dissociation, 6(3), 83-104.

Fritz, H. L., Nagurney, A. J., \& Helgeson, V. S. (2003). Social interactions and cardiovascular reactivity during problem disclosure among friends. Personality and Social Psychology Bulletin, 29, 713-725.

Goldberg, L. R., \& Freyd, J. J. (2006). Self-reports of potentially traumatic experiences in an adult community sample: Gender differences and test-retest stabilities of the items in a Brief Betrayal Trauma Survey. Journal of Trauma \& Dissociation, 7(3), $39-63$.

Green, B. L., Goodman, L. A., Krupnick, J. L., Corcoran, C. B., Petty, R. M., Stockton, P., \& Stern, N. M. (2000). Outcomes of single versus multiple trauma exposure in a screening sample. Journal of Traumatic Stress, 13, 271-286.

Hansen, F. C., Resnick, H., \& Galea, J. (2002). Better listening: Paraphrasing and perception checking - A study of the effectiveness of a multimedia skills training program. Journal of Technology in Human Services, 20, 317-331.

Hatcher, S. L., Nadeau, M. S., Walsh, L. K., Reynolds, M., Galea, J., \& Marz, K. (1994). The teaching of empathy for high school and college students: Testing Rogerian methods with the Interpersonal Reactivity Index. Adolescence, 29, 961-974.

Heaven, P., \& Ciarrochi, J. (2007). Personality and religious values among adolescents: A three-wave longitudinal analysis. British Journal of Psychology, 98, 681-694.

Hemenover, S. H. (2003). The good, the bad, and the healthy: Impacts of emotional disclosure of trauma on resilient self-concept and psychological distress. Personality and Social Psychology Bulletin, 29, 1236-1244.

Hogan, B. E., Linden, W., \& Najarian, B. (2002). Social support interventions: Do they work? Clinical Psychology Review, 22, 381-440.
Hussong, A. M., \& Hicks, R. E. (2003). Affect and peer context interactively impact adolescent substance use. Journal of Abnormal Child Psychology, 31, 413-426.

Ingram, K. M., Betz, N. E., Mindes, E. J., Schmitt, M. M., \& Smith, N. G. (2001). Unsupportive responses from others concerning a stressful life event: Development of the Unsupportive Social Interactions Inventory. Journal of Social and Clinical Psychology, 20, 173-207.

Janusik, L. (2008). Introduction to listening in context. International Journal of Listening, 22, $99-$ 102.

Judd, J. M., McClelland, G. H., \& Ryan, C. S. (2009). Models with continuous and categorical predictors: ANOVA. In Data analysis: A model comparison approach (pp. 219-246). New York, NY: Routledge.

Kenny, D. A., Kashy, D. A., \& Cook, W. L. (2006). Dyadic data analysis. New York, NY: Guilford.

King, M. G., Burrows, G. D., \& Stanley, G. V. (1983). Measurement of stress and arousal: Validation of the Stress/Arousal Adjective Checklist. British Journal of Psychology, 74, 473-479.

Lantz, P. M., House, J. S., Mero, R. P., \& Williams, D. R. (2005). Stress, life events, and socioeconomic disparities in health: Results from the Americans' Changing Lives Study. Journal of Health and Social Behavior, 46, 274-288.

Lepore, S. J., Fernandez-Berrocal, P., Ragan, J., \& Ramos, N. (2004). It's not that bad: Social challenges to emotional disclosure enhance adjustment to stress. Anxiety, Stress, and Coping, 17, 341361.

Lepore, S. J., Ragan, J. D., \& Jones, S. (2000). Talking facilitates cognitive-emotional processes of adaptation to an acute stressor. Journal of Personality and Social Psychology, 78, 499-508.

Mackay, C., Cox, T., Burrows, G., \& Lazzerini, T. (1978). An inventory for the measurement of selfreported stress and arousal. British Journal of Social and Clinical Psychology, 17, 283-284.

Major, B., Cozzarelli, C., Sciacchitano, A. M., Cooper, M., \& Testa, M. (1990). Perceived social support, self-efficacy, and adjustment to abortion. Journal of Personality and Social Psychology, 59, 452-463.

Mindes, E. J., Ingram, K. M., Kliewer, W., \& James, C. A. (2003). Longitudinal analyses of the relationship between unsupportive social interactions and psychological adjustment among women with fertility problems. Social Science \& Medicine, 56, 2165-2180.

New Jersey Self-Help Group Clearinghouse. (n.d.). Improving your listening skills. In New Jersey Self-Help Group Clearinghouse library of downloadable "how-to" group literature. Retrieved from http://www.njgroups.org/ 
Pistrang, N., Barker, C., \& Rutter, C. (1997). Social support as conversation: Analysing breast cancer patients' interactions with their partners. Social Science \& Medicine, 45, 773-782.

Pollak, K. I., Arnold, R. M., Jeffreys, A. S., Alexander, S. C., Olsen, M. K., Abernethy, A. P., ... Tulsky, J. A. (2007). Oncologist communication about emotion during visits with patients with advanced cancer. Journal of Clinical Oncology, 25, $5748-5752$.

Resnick, H. (1998). Paraphrase II: A listening skills training program for human services students. Computers in Human Services, 15, 89-96.

Rime, B. (1995). Mental rumination, social sharing, and the recovery from emotional exposure. In J. W. Pennebaker (Ed.), Emotion, disclosure, and health (pp. 271-292). Washington, DC: American Psychological Association.

Robertson, K. (2005). Active listening-More than just paying attention. Australian Family Physician, 34, 1053-1055.

Smith, R. C., \& Hoppe, R. B. (1991). The patient's story: Integrating the patient- and physiciancentered approaches to interviewing. Annals of Internal Medicine, 115, 470-477.

Taheri, S. (2006). The link between short sleep duration and obesity: We should recommend more sleep to prevent obesity. Archives of Disease in Childhood, 91, 881-884.

Taylor, L. K., Cook, P. F., Green, E. E., \& Rogers, J. K. (2001). Better interviews: The effects of supervisor training on listening and collaborative skills. Journal of Educational Research, 82, 89-95.

U.S. Department of Health and Human Services. (1996). Physical activity and health: A report of the Surgeon General. Atlanta, GA: U.S. Department of Health and Human Services, Public Health Service, Centers for Disease Control and Prevention, National Center for Chronic Disease Prevention and Health Promotion.

U.S. Department of Health and Human Services \& U.S. Department of Agriculture. (2005). Dietary guidelines for Americans (6th ed.). Washington, DC: U.S. Government Printing Office.

Ullman, S. E. (2007). Relationship to perpetrator, disclosure, social reactions, and PTSD symptoms in child sexual abuse survivors. Journal of Child Sexual Abuse, 16, 19-36.

Ullman, S., \& Filipas, H. (2001). Correlates of formal and informal support seeking in sexual assault victims. Journal of Interpersonal Violence, 16, $1028-1047$.

Watson, D., \& Clark, L. A. (1994). Measurement and mismeasurement of mood: Recurrent and emergent issues. Journal of Personality Assessment, 68, 267-296.

Yager, J., \& Thorpy, M. J. (2001). Sleeping well: The sourcebook for sleep and sleep disorders. New York: Facts on File.

Received June 13, 2010 Revision received October 15, 2010 Accepted October 15, 2010 